\title{
Comparative Analyses of Effects of Posture Variations on Neuromuscular Efficiency of Para-vertebral Muscles in Patients with Low Back Pain
}

\author{
Onigbinde Ayodele Teslim ${ }^{1}$, Ayanlade Osuolale Basiru ${ }^{2}$, Olaoye Ayoola Olumide ${ }^{1}$, \\ Ibikunle Adeoye Folorunsho ${ }^{3}$ \\ ${ }^{1}$ Department of Medical Rehabilitation, Faculty of Basic Medical Sciences, College of Health Sciences, Obafemi Awolowo University, \\ Ile-Ife, Nigeria \\ ${ }^{2}$ Department of Physiotherapy, University of Calabar Teaching Hospital, Calabar, Nigeria \\ ${ }^{3}$ Department of Physiotherapy, Obafemi Awolowo University Teaching Hospitals Complex, Ile-Ife, Nigeria
}

Email address:

ayotesonigbinde@yahoo.co.uk (O. A. Teslim)

\section{To cite this article:}

Onigbinde Ayodele Teslim, Ayanlade Osuolale Basiru, Olaoye Ayoola Olumide, Ibikunle Adeoye Folorunsho. Comparative Analyses of Effects of Posture Variations on Neuromuscular Efficiency of Para-vertebral Muscles in Patients with Low Back Pain. European Journal of Clinical and Biomedical Sciences. Vol. 3, No. 1, 2017, pp. 24-33. doi: 10.11648/j.ejcbs.20170301.15

Received: September 30, 2016; Accepted: October 15, 2016; Published: March 2, 2017

\begin{abstract}
This study investigated the neuromuscular efficiency of patients with Low Back Pain (LBP) at different spinal postures using electromyographic indices [Spinal Muscle Electrical Activities (SMEA) and Root Mean Square (RMS)]. This was with the view to establishing if there would be significant differences between SMEA of patients with Low Back Pain (LBP) and that of apparently healthy participants at different spinal postures. Thirty (30) patients with non - specific low back pain and 32 apparently healthy participants were recruited using purposive sampling technique. The SMEA and RMS at different spinal postures (erect standing, $30^{\circ}, 45^{\circ}, 90^{\circ}$ spinal flexions and $30^{\circ}$ spinal extension) were measured with a portable electromyography machine (MyoTrac infiniti System T 9800). Spinalflexion was measured with universal goniometer while pain intensity was measured using Numeric Pain Rating Scale. Disposable pregelled, tripolar, self-adhesive Ag/Agcl electrodes were placed in pairs with distance of $2 \mathrm{~cm}$ from each other and parallel to the Longissimusdorsi and multifidus muscle fibers. The Spinal Muscle Electrical Activities were recorded for each participant at each of the postures while maintaining maximum voluntary contraction for 10 seconds. Descriptive statistics, Student t-test and Analysis of Variance were used to analyze the data. The level of significance was set at $\leq 0.05$. There were significant differences in SMEA and RMS at different spinal postures among patients with LBP $(F=29.20, p=0.001 ; F=40.55$ respectively, $p=0.001)$. The SMEA of patients with LBP were significantly lower at all postures compared to that of the age matched apparently healthy participants excluding at $30^{\circ}$ spinal extension $(\mathrm{t}=2.04, \mathrm{p}=0.05 ; \mathrm{t}=-0.20 ; \mathrm{p}=0.84)$. Also, there were significant differences between the RMS of patients with LBP and the age matched apparently healthy participants at $30^{\circ}, 45^{\circ}$ and $90^{\circ}$ spinal flexion $(\mathrm{t}=2-79, \mathrm{p}=0.01 ; \mathrm{t}=2.61, \mathrm{p}$ $=0.01 ; \mathrm{t}=5.19 ; \mathrm{p}=0.001$ respectively). It was concluded that different postures affected neuromuscular efficiency of patients with low back pain. Also, neuromuscular efficiency at the para-vertebral muscles of low back pain patients for most spinal postures were significantly lower than that of the apparently healthy participants.
\end{abstract}

Keywords: Spinal Muscle Electrical Activities, Root Mean Square, Low Back Pain, Spinal Postures, Neuromuscular Efficiency

\section{Introduction}

There was strong evidence that posture is a risk factor for the development of musculoskeletal disorders and this accounts for essentiality of postural assessment while managing patients with low back pain (LBP), [1-3]. Posture affects the spine in different ways, although, there are conflicting reports on relationship between posture and LBP. There are emerging evidence in-vivo that links the two, and that certain postures are associated with direction specific exercises [3-9]. There is also documentation that hip and 
knee flexion posture causes posterior tilting of the pelvis, which in turn produces a flattening of the lumbar lordosis [10]. Furthermore, different spinal postures, muscle activity, and passive support alter the forces generated in the spine [11].

The major bane of management of LBP is accurate diagnosis considering the wide range of aetiologies and causative factors, and other dysfunction which may mimic the symptoms [12]. Back muscles assessment is an essential part of evaluation process for identifying physical impairments and postures in patients with LBP syndromes. There are numerous ways of analyzing posture and this includes mechanical indices such as direct observation, measurement with goniometer and video-computer analysis [10], [13-14]. However, surface electromyographic signal provides a more objective measure of muscle performance than the mechanical indices [15-17].

An EMG assesses the electrical activity of a nerve root and it is currently being considered for patients with back pain in medical rehabilitation and it is a measure of neuromuscular efficiency [18]. The muscle impairments in patient with LBP disorders could be distinguished from normal muscle functioning in subjects without LBP with 90\% accuracy based solely on median frequency parameters [18-19]. The recording signal provides understanding for muscle activities under normal and pathological conditions by analyzing; and classifying the EMG especially when motion occurs [19]. Amongst indices of EMG are the Root Mean Square [RMS] and variability. The Root Mean Square (RMS)is considered to provide the most insight on the amplitude of the EMG signal and gives a measure of the power of the signal in the motor unit during contraction while variability refers to difference in variations in electrical signals of muscles where surface electrodes are attached for EMG measurement [2021]. In statistics and its applications, the root mean square (abbreviated RMS or rms) is defined as the square root of mean square (the arithmetic mean of the squares of a set of numbers), [22]. However, in most clinical practices, there is dearth of adequate empirical data on the use of EMG indices to determine neuromuscular efficiency of para-vertebral muscles in patients with LBP. There is also dearth of a systematic review that has identified the postures that aggravates or relieves low back pain [23]. Furthermore, identifying the pathogenesis of low back pain is a challenging task due to the complex anatomy of the back. Electromyography has been reported to provide evidence of physiological phenomena related to the back musculature but there is paucity of reports on spinal EMG that could serve as clinical outcome measure to guide management techniques. The aims of this study were to determine and compare the Spinal Muscle Electrical Activities (SMEA), RMS and variability of patients having low back pain with that of apparently healthy participants at different postures. It was hypothesized that there would be no significant difference in SMEA, RMS and variability of patients with low back pain and that of apparently healthy participants.

\section{Methodology}

\subsection{Participants}

Participants were 30 patients with non-specific low back pain recruited from outpatient physiotherapy clinics of University of Calabar Teaching and state hospitals, Calabar, Cross River State in South-south Nigeria and; 32 apparently healthy participants matched by sex and age (control) with the patients.

\subsection{Research Design}

The design was a quasi-experimental research because there was no intervention.

\subsection{Inclusion and Exclusion Criteria}

The major criteria were that the clinical diagnoses of nonspecific LBP must be made by an orthopeadic surgeon, duration of onset equal or greater than three months, participants must be 20 years and older; and healthy participants must be without spinal musculoskeletal injury and back pain. Excluded were patients who have had back/lumbar spine surgeries, anterior derangement, hip replacement, dislocation or fracture and those with red and yellow flags. Also excluded were patients with acute inflammation, tumors, bone fracture, peripheral vascular diseases, and internal fixation. All patients with diagnoses of cardiovascular and pulmonary diseases such as high blood pressure, cardiac conditions, asthma, dyspnea, bronchitis and pneumonia, those suffering from diseases of the spinal cord, Pott's diseases, neurological and metabolic diseases such as diabetes neuropathies were excluded from the study.

\subsection{Sampling Technique}

Purposive sampling technique was used to recruit participants who met all the inclusion criteria.

\subsection{Instruments}

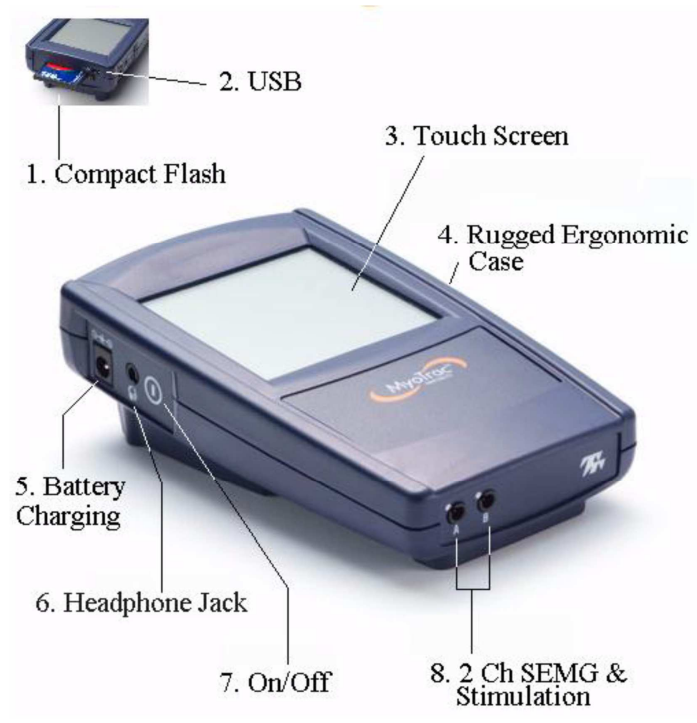

Figure 1. MyoTrac infiniti. 
The main instrument utilized was MyoTrac infiniti System T9800 (Thought Technology Limited 2180, Belgrave Avenue Montreal, Quebec Canada H4A2L8 (Figure 1). Height and weight were measured using Stadiometer (Leaidal Medicals in England, Serial no. NB -160), (calibrated in centimeter for height measurement but values obtained were converted to meter and weight in kilogram). A universal goniometer was used to measure the range of motion at spine while the participants performed forward flexion at $30^{\circ}, 45^{\circ}, 90^{\circ}$ flexion and $30^{\circ}$ extension postures.

The universal goniometer had been documented to have excellent reliability and construct validity with inclinometer $[24,25]$. Others were a 10 -point numeric pain rating scale, methylated spirit and cotton wool used for cleaning the body surface before applying EMG electrodes.

\subsection{Procedure}

Ethical Clearance was obtained from the University of Calabar Teaching Hospital, Calabar, Cross River State, Nigeria. Consent was obtained while purpose and protocol for the study were explained to the participants. The participants' ages, weight, height, electrical activities of the muscles, spinal flexion/extension, and pain intensity assessment were taken and recorded, the body mass index (BMI) was deduced mathematically by dividing weight with square of height. Height was recorded to the nearest $0.1 \mathrm{~m}$. The participants were asked to remove their shoes and their heels were positioned against the wall, with their scapula, buttocks and heels resting against the wall. The weight of the participant's was measured to the nearest $0.1 \mathrm{~kg}$. Other measurements were also determined using standard procedures. EMG was used to measure muscle electromyographic activities (SMEA, RMS and Variability), while spinal flexion and extension were measured using universal goniometer and Visual Analogue Scale (VAS) was used to assess pain intensity. The lumbar area of the spine was washed with soap and water, dried with towel and cleansed with moist cotton wool that was immersed in methylated spirit to reduce skin impedance. Jewelries or any metallic objects were removed from the participant's body. Appropriate draping of the participants was ensured. To record muscle activity, disposable, tripolar, self-adhesive $\mathrm{Ag} / \mathrm{Agcl}$ electrodeswere placed in pairs with distance of $2 \mathrm{cmfrom}$ each other and parallel to the muscle fibers [26], lateral to spinous process of L3; and parallel to the vertebral column on the muscle belly with a pair of reference electrode at inferior angle of scapular(T7), a pair of active electrode at level of L1L2, and a pair of indifference electrodes at the level of L4, L5. The first paired electrodes were placed on the skin overlying the para-spinal muscles at $\mathrm{T} 7$ (inferior angle of scapula), second pair at L1/L2 and third pair at L4/L5vertebrae levels. The EMG activities were picked up by the surface electrodes on the lumbar muscles at $\mathrm{T} 7$ and between L1/L5 vertebral levels and values obtained were recorded in microvolt with the participants in erect standing position, at $30^{\circ}, 45^{\circ}, 90^{\circ}$ flexion and $30^{\circ}$ extension positions. The patients maintained each of these positions for ten seconds maintaining maximum contraction. The same procedure of electrode placement was used to measure the EMG activities of spinal muscles of apparently healthy individual. The spinal ranges of motions were measured for each participant with a goniometer, and this is defined as the angle between the subject's femur and the mid-axillary line [27].

The apparently healthy participants were screened to exclude pathology at the back using physical diagnostic tests: compression, modified sit and reach for spinal flexibility, Lasegue's (straight leg raising), Ely's (Reverse SLR), anterior-posterior digital pressure tests on lumbar spine, sacroiliac compression and distraction test, skin rolling test, and pelvic in-nominate test. Participants that tested positive were excluded from the study.

\subsection{Statistical Analysis}

Descriptive statistics was used to determine the mean and standard deviation of the ages, height, weight, BMI, pain intensity, SMEA, RMS and Variability. Student t-test was used to compare values obtained for patients and apparently healthy participants (controls). Analysis of variance (ANOVA) was used to compare values obtained at erect standing, spinal flexion at $30^{\circ}, 45^{\circ}, 90^{\circ}$ flexion and $30^{\circ}$ extension postures. Pearson Product Moment Correlation Coefficient was used to determine the relationship between each of pain intensity, duration of onset, SMEA, RMS and Variability of spinal muscles of patients with low back pain. Alpha $(\alpha)$ level was set at 0.05 . SPSS version 22 software (SPSS Inc., Chicago, Illinois, USA) was used.

\section{Results}

The result showed that there are $22(68.8 \%)$ male and 10 $(31.3 \%)$ female in the apparently healthy control group while there are $18(60.0 \%)$ male and $12(40 \%)$ female among the patients with LBP. The mean duration of onset of LBP was $38.00 \pm 15.29$ (weeks). The mean weight, height and body mass index (BMI) of both patients with LBP and control group are presented in Table 1 . The result of independent $t$ test showed that the participants in the two groups were comparable in age, height and BMI (Table 1).

Table 1. Physical characteristics of patients with LBP and apparently healthy participants.

\begin{tabular}{lllll}
\hline & Patient Group & Control Group & & \\
\hline & $\mathrm{n}=30$ & $\mathrm{n}=32$ & & \\
Variables & Mean SD & Mean SD & $\mathrm{t}$ & $\mathrm{p}$ \\
Age (years) & $42.28 \pm 5.63$ & $43.03 \pm 8.03$ & 0.42 & 0.68 \\
Height $($ meters $)$ & $1.68 \pm 0.60$ & $1.70 \pm 0.07$ & 1.00 & 0.32 \\
Weight $(\mathrm{kg})$ & $80.12 \pm 9.75$ & $79.53 \pm 11.38$ & 0.22 & 0.83 \\
BMI $\left(\mathrm{kg} / \mathrm{m}^{2}\right)$ & $28.43 \pm 3.72$ & $27.69 \pm 0.76$ & 0.76 & 0.45 \\
\hline
\end{tabular}

\subsection{Pain Intensity at Different Spinal Postures Among Patients with $L B P$}

The pain intensities experienced by the patients at different 
spinal postures are presented in table 2. Participants' pain intensities differed significantly across different spinal postures $(\mathrm{F}=9.30, \mathrm{p}=0.001)$. Pain intensities were significantly higher at $30^{\circ}, 45^{\circ}, 90^{\circ}$, spinal flexion and $30^{\circ}$ spinal extension than at erect standing $(\mathrm{p}=0.01, \mathrm{p}=$ $0.001, \mathrm{p}=0.001, \mathrm{p}=0.001$ respectively (Table 3 ). The graphical illustration of pain intensities at different postures is presented in Figure 2.

Table 2. Pain intensity at different Postures among Patients with Low Back Pain.

\begin{tabular}{llllll}
\hline \multicolumn{7}{c}{$\begin{array}{l}\text { Pain } \\
\text { Intensity }\end{array}$} & & & \\
\hline Spinal posture & Minimum & Maximum & Mean SD & F & p \\
\hline Erect standing & 0.00 & 7.00 & $1.97 \pm 1.71$ & & \\
$30^{\circ}$ Spinal flex & 0.00 & 8.00 & $3.30 \pm 1,80$ & & \\
$45^{\circ}$ Spinal flex & 1.00 & 8.00 & $3.90 \pm 1.86$ & & \\
$90^{\circ}$ Spinal flex & 1.00 & 9.00 & $4.73 \pm 2.27$ & & \\
$30^{\circ}$ Spinal ext. & 1.00 & 10.00 & $4.70 \pm 2.53$ & 9.30 & $0.001^{* *}$ \\
\hline
\end{tabular}

flex; flexion, ext; extension, $* *$ significant at 0.001 level.

Table 3. Post Hoc analyses comparing pain intensity at different postures for patient with low back pain.

\begin{tabular}{llll}
\hline Postures & & & \\
\hline i Group & j Group & Mean change & p \\
\hline Erect standing posture & 2 & -1.33 & $0.01^{*}$ \\
& 3 & -1.93 & $0.001^{* *}$ \\
& 4 & -2.77 & $0.001^{* *}$ \\
$30^{\circ}$ spinal flexion & 5 & -2.73 & $0.001^{* *}$ \\
& 3 & -0.60 & 0.26 \\
& 4 & -1.43 & $0.01^{*}$ \\
$45^{\circ}$ spinal flexion & 5 & -1.40 & $0.01^{*}$ \\
& 4 & -0.83 & 0.12 \\
$90^{\circ}$ spinal flexion & 5 & -0.8 & 0.14 \\
\hline
\end{tabular}

*significant at 0.01 level, **significant at 0.001 level

\subsection{Comparison of Spinal Muscle Electrical Activities, Root Mean Square and Variability at Different Postures Among Patients with LBP}

The mean SMEA obtained at erect standing was $18.78 \pm$ 13.30 microvolt $(\mu \mathrm{v})$ while at $30^{\circ}$ spinal flexion and $30^{\circ}$ spinal extensions were $46.35 \pm 17.77 \mu \mathrm{v}$ and $20.64 \pm 23.32$ $\mu v$ respectively. Other values are presented in Table 4 . There were significant differences in SMEA at different spinal postures among patients with LBP $(\mathrm{F}=29.20, \mathrm{p}=0.001)$ (Table 4). The graph showing SMEA of patients with LBP at different spinal postures is presented in Figure 2. The result of the Post Hoc analysis (LSD) showed that the SMEA at $30^{\circ}$, and $45^{\circ}$ spinal flexion were significantly higher compared to erect standing $(p=0.001$ and $p=0.001$ respectively).

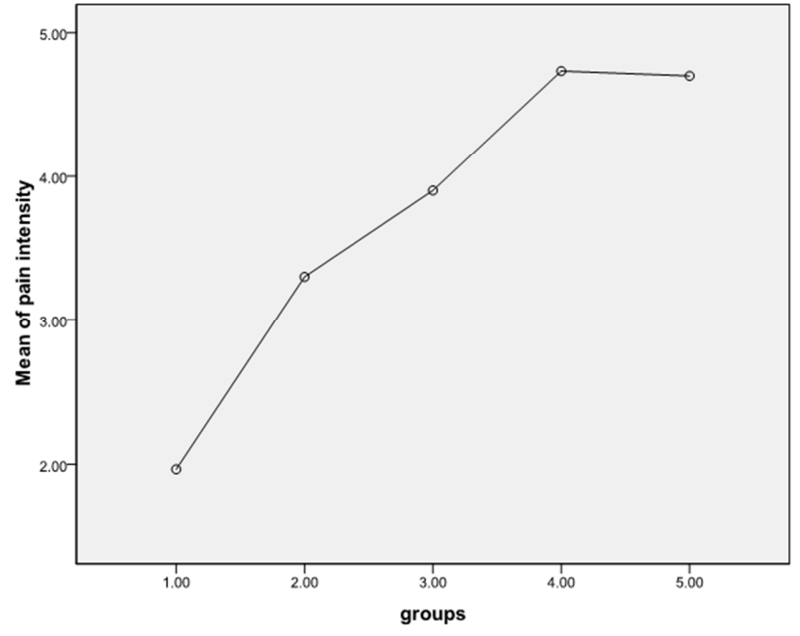

Figure 2. Graphical illustration of mean pain intensity for the LBP patients.

1: is erect standing posture, $2: 30^{\circ}$ spinal flexion, $3: 45^{\circ}$ spinal flexion, 4 : $90^{\circ}$ spinal flexion and 5: $30^{\circ}$ spinal extension.

The mean Root Mean Square (RMS) at erect standing was $22.01 \pm 14.93 \mu \mathrm{v}$ while at $30^{\circ}$ spinal flexion and $30^{\circ}$ spinal extensions they were $47.60 \pm 17.75 \mu \mathrm{v}$ and $15.14 \pm 13.45 \mu \mathrm{v}$ respectively. There were significant differences in RMS at different spinal postures among patients with LBP (F = $40.55, \mathrm{p}=0.001$ ), (Table 4). The result of the Post Hoc analysis (LSD) showed that the RMS at $30^{\circ}$, and $45^{\circ}$ spinal flexion were significantly higher than at erect standing $(\mathrm{p}=$ 0.001 and $\mathrm{p}=0.001$ respectively). The RMS at $90^{\circ}$ spinal flexion and $30^{\circ}$ spinal extension were significantly higher compared to at $30^{\circ}$ spinal flexion $(\mathrm{p}=0.001, \mathrm{p}=0.001$ respectively). However, RMS at $90^{\circ}$ spinal flexion and $30^{\circ}$ spinal extension were significantly higher compared to at $45^{\circ}$ spinal flexion ( $\mathrm{p}=0.001, \mathrm{p}=0.001$ respectively), (Table 5).

The mean variability was $0.20 \pm 0.13 \mu \mathrm{v}$ at erect standing while at $30^{\circ}$ spinal flexion and $30^{\circ}$ spinal extensions they were $0.10 \pm 0.02 \mu \mathrm{v}$ and $0.35 \pm 0.06 \mu \mathrm{v}$ respectively. There were significant differences in variability at different spinal postures among patients with LBP $(\mathrm{F}=4.41, \mathrm{p}=0.002)$, (Table 4). The result of the Post Hoc analysis (LSD) showed that the variabilityat $30^{\circ}$ extension was significantly higher than at erect standing $(\mathrm{p}=0.004)$. Also, the variability at $90^{\circ}$ spinal flexion and $30^{\circ}$ extension were significantly higher compared to at $30^{\circ}$ spinal flexion $(\mathrm{p}=0.03, \mathrm{p}=0.001$ respectively). Furthermore, variability at $90^{\circ}$ spinal flexion and $30^{\circ}$ extension were significantly higher compared to at $45^{\circ}$ spinal flexion $(\mathrm{p}=0.05, \mathrm{p}=0.001$ respectively). Other results were shown in Table 5 .

\subsection{Comparison of Spinal Muscle Electrical Activities, Root Mean Square and Variability at Different Postures Among Apparently Healthy Participants}

The mean SMEA was $27.46 \pm 19.37 \mu \mathrm{v}$ at erect standing for apparently healthy control subjects while the mean spinal muscle electrical activities at $30^{\circ}, 45^{\circ}, 90^{\circ}$ spinal flexion's 
and $30^{\circ}$ spinal extension are presented in Table 6 . Figure 3 shows SMEA graph of apparently healthy participants at different spinal postures. The result of ANOVA showed that there were significant differences in the SMEA at different postures of participant in the control group $(F=45.39, p=$ 0.001). The post Hoc analysis (LSD) showed that SMEA at $30^{\circ}$ and $45^{\circ}$ spinal flexion were significantly higher compared to at erect standing $(\mathrm{p}=0.001$, and $\mathrm{p}=0.001$ respectively). The SMEA at $90^{\circ}$ spinal flexion and $30^{\circ}$ extensionwere significantly higher compared to at $30^{\circ}$ spinal flexion ( $p=0.001 ; p=0.001)$. However, SMEA at $90^{\circ}$ spinal flexion and $30^{\circ}$ spinal extensionwere significantly higher compared to $45^{\circ}$ spinal flexion $(\mathrm{p}=0.001 ; \mathrm{p}=0.001)$. Other results are shown in Table 7.

The mean RMS and variability for apparently healthy control at $30^{\circ}, 45^{\circ}, 90^{\circ}$ spinal flexion's and $30^{\circ}$ spinal extension are presented in Table 6 and 7. The result of ANOVA showed that there were significant differences in the RMS at different postures of participant in the control group $(\mathrm{F}=23.36, \mathrm{p}=0.001)$. The post Hoc analysis (LSD) showed that RMS at $45^{\circ}$ spinal flexion was significantly higher compared to at erect standing $(\mathrm{p}=0.001)$. RMS at $45^{\circ}$ spinal flexion was significantly higher compared to at $30^{\circ}$ spinal flexion $(\mathrm{p}=0.001)$. Furthermore RMS at and $30^{\circ}$ spinal extension was significantly higher compared to at $30^{\circ}$ spinal flexion. The RMS at $90^{\circ}$ spinal flexion and $30^{\circ}$ spinal extensionwere significantly higher compared to $45^{\circ}$ spinal flexion $(p=0.001 ; p=0.001)$. The result of ANOVA showed that there were no significant differences in the variability at different spinal postures of apparently healthy participant in the control group $(F=1.91, p=0.11)$.

Table 4. Comparison of SMEA, RMS and Variability at Different Postures Among Patients with LBP.

\begin{tabular}{|c|c|c|c|c|c|}
\hline Postures & Minimum & Maximum & Mean SD & $\mathbf{F}$ & $\mathbf{P}$ \\
\hline SMEA:Erect & 4.78 & 55.95 & $18.78 \pm 13.30$ & & \\
\hline $30^{\circ} \mathrm{f}$ & 18.71 & 80.80 & $46.35 \pm 17.77$ & & \\
\hline $45^{\circ} \mathrm{f}$ & 5.10 & 83.74 & $48.35 \pm 20.83$ & & \\
\hline $90^{\circ} \mathrm{f}$ & 1.33 & 21.30 & $10.74 \pm 6.99$ & & \\
\hline $30^{\circ} \mathrm{ext}$ & 3.83 & 93.31 & $20.64 \pm 23.32$ & 29.20 & $0.001 * *$ \\
\hline RMS: Erect & 5.05 & 60.31 & $22.01 \pm 14.93$ & & \\
\hline $30^{\circ} \mathrm{f}$ & 9.16 & 83.44 & $47.60 \pm 17.75$ & & \\
\hline $90^{\circ} \mathrm{f}$ & 3.50 & 29.80 & $16.70 \pm 6.62$ & & \\
\hline $30^{\circ} \mathrm{ext}$ & 0.86 & 64.12 & $15.14 \pm 13.45$ & 40.55 & $0.001 * *$ \\
\hline VARI: Erect & 0.05 & 0.67 & $0.20 \pm 0.13$ & & \\
\hline $30^{\circ} \mathrm{f}$ & 0.09 & 0.62 & $0.10 \pm 0.02$ & & \\
\hline $45^{\circ}$ & 0.11 & 0.52 & $0.09 \pm 0.02$ & & \\
\hline $90^{\circ} \mathrm{f}$ & 0.11 & 2.58 & $0.45 \pm 0.08$ & & \\
\hline $30^{\circ} \mathrm{ext}$ & 0.03 & 1.55 & $0.35 \pm 0.06$ & 4.41 & $0.002 *$ \\
\hline
\end{tabular}

SMEA: spinal muscle electrical activities; RMS: root mean square; VARI: variability; ${ }^{*}$ significant at 0.05 level,**significant at 0.001 level

Table 5. Comparison of SMEA, RMS and Variability at different postures among patients with LBP post hoc analysis.

\begin{tabular}{|c|c|c|c|}
\hline \multicolumn{4}{|l|}{ Postures } \\
\hline i Group & j Group & Mean change & $\mathbf{p}$ \\
\hline \multirow[t]{4}{*}{ SMEA: 1} & 2 & -27.57 & $0.001 * *$ \\
\hline & 3 & -29.57 & $0.001 * *$ \\
\hline & 4 & 8.04 & 0.08 \\
\hline & 5 & -1.86 & 0.68 \\
\hline \multirow[t]{3}{*}{2} & 3 & 2.01 & 0.66 \\
\hline & 4 & 35.69 & $0.001 * *$ \\
\hline & 5 & 25.71 & $0.001 * *$ \\
\hline \multirow[t]{2}{*}{3} & 4 & 37.61 & $0.001 * *$ \\
\hline & 5 & 27.72 & $0.001 * *$ \\
\hline 4 & 5 & -9.89 & $0.03 *$ \\
\hline \multirow[t]{4}{*}{ RMS:1 } & 2 & -25.59 & $0.001 * *$ \\
\hline & 3 & -29.93 & $0.001 * *$ \\
\hline & 4 & 5.31 & 0.18 \\
\hline & 5 & 6.87 & 0.08 \\
\hline \multirow[t]{3}{*}{2} & 3 & -4.34 & 0.27 \\
\hline & 4 & 30.90 & $0.001 * *$ \\
\hline & 5 & 32.46 & $0.001 * *$ \\
\hline \multirow[t]{2}{*}{3} & 4 & 35.24 & $0.001 * *$ \\
\hline & 5 & 36.79 & $0.001 * *$ \\
\hline 4 & 5 & 1.55 & 0.69 \\
\hline \multirow[t]{4}{*}{ VARIA: 1} & 2 & 0.03 & 0.62 \\
\hline & 3 & 0.02 & 0.73 \\
\hline & 4 & -0.12 & 0.1 \\
\hline & 5 & -0.20 & $0.004 *$ \\
\hline
\end{tabular}




\begin{tabular}{llll}
\hline 2 & 3 & -0.01 & 0.87 \\
& 4 & -0.15 & $0.03^{*}$ \\
& 5 & -0.24 & $0.001^{* *}$ \\
3 & 4 & -0.14 & $0.05^{*}$ \\
& 5 & -0.23 & $0.001^{* *}$ \\
\hline
\end{tabular}

SMEA: spinal muscle electrical activities; RMS: root mean square; VARIA: variability;

1 ; Erect standing posture;2;30 spinal flexion, $3 ; 45^{\circ}$ spinal flexion; $4 ; 90^{\circ}$ spinal flexion and5 is $30^{\circ}$ spinal extension.; * significant at 0.05 level.**significant at 0.001 level

Table 6. Comparison of SMEA, RMS and Variability at different spinal postures among apparently healthy participants.

\begin{tabular}{|c|c|c|c|c|c|}
\hline Postures & Minimum & Maximum & Mean SD & $\mathbf{F}$ & $\mathbf{P}$ \\
\hline SMEA:Erect & 6.48 & 87.30 & $27.46 \pm 19.37$ & & \\
\hline $30^{\circ} \mathrm{f}$ & 25.89 & 102.94 & $62.54 \pm 19.12$ & & \\
\hline $45^{\circ} \mathrm{f}$ & 6.84 & 113.69 & $60.70 \pm 22.40$ & & \\
\hline $90^{\circ} \mathrm{f}$ & 2.13 & 35.00 & $21.13 \pm 7.34$ & & \\
\hline $30^{\circ} \mathrm{ext}$ & 2.78 & 74.16 & $19.59 \pm 18.32$ & 45.39 & $0.001 * *$ \\
\hline RMS: Erect & 1.78 & 73.01 & $27.92 \pm 18.01$ & & \\
\hline $30^{\circ} \mathrm{f}$ & 2.92 & 98.08 & $33.15 \pm 22.51$ & & \\
\hline $45^{\circ} \mathrm{f}$ & 4.44 & 151.01 & $67.72 \pm 27.02$ & & \\
\hline $90^{\circ} \mathrm{f}$ & 1.47 & 64.33 & $30.91 \pm 13.54$ & & \\
\hline $30^{\circ} \mathrm{ext}$ & 2.53 & 83.52 & $22.55 \pm 21.38$ & 23.36 & $0.001 * *$ \\
\hline VARI: Erect & 0.03 & 0.67 & $0.15 \pm 0.13$ & & \\
\hline $30^{\circ} \mathrm{f}$ & 0.09 & 0.82 & $0.15 \pm 0.12$ & & \\
\hline $45^{\circ}$ & 0.05 & 0.34 & $0.15 \pm 0.05$ & & \\
\hline $90^{\circ} \mathrm{f}$ & 0.02 & 1.73 & $0.21 \pm 0.29$ & & \\
\hline $30^{\circ} \mathrm{ext}$ & 0.03 & 2.86 & $0.30 \pm 0.49$ & 1.91 & 0.11 \\
\hline
\end{tabular}

Key: SMEA: spinal muscle electrical activities; RMS: root mean square; VARIA: variability; f: flexion; ext: extension, *significant at 0.05 level, **significant at 0.001 level.

Table 7. Post Hoc Analysis Comparing SMEA, RMS and Variability at Different Postures Among Apparently Healthy Participants.

\begin{tabular}{|c|c|c|c|}
\hline \multicolumn{4}{|l|}{ Postures } \\
\hline i Group & j Group & Mean change & $\mathbf{P}$ \\
\hline \multirow[t]{4}{*}{ SMEA: 1} & 2 & -35.09 & $0.001 * *$ \\
\hline & 3 & -33.25 & $0.001 * *$ \\
\hline & 4 & 6.32 & 0.16 \\
\hline & 5 & 7.87 & 0.08 \\
\hline \multirow[t]{3}{*}{2} & 3 & 1.84 & 0.68 \\
\hline & 4 & 41.41 & $0.001 * *$ \\
\hline & 5 & 49.95 & $0.001 * *$ \\
\hline \multirow[t]{2}{*}{3} & 4 & 39.52 & $0.001 * *$ \\
\hline & 5 & 41.11 & $0.001 * *$ \\
\hline 4 & 5 & 1.54 & 0.73 \\
\hline \multirow[t]{4}{*}{ RMS:1 } & 2 & -5.24 & 0.32 \\
\hline & 3 & -39.81 & $0.001 * *$ \\
\hline & 4 & -2.99 & 0.57 \\
\hline & 5 & 5.37 & 0.31 \\
\hline \multirow[t]{3}{*}{2} & 3 & -34.57 & $0.001 * *$ \\
\hline & 4 & 2.24 & 0.67 \\
\hline & 5 & 10.60 & $0.05^{*}$ \\
\hline \multirow[t]{2}{*}{3} & 4 & 36.82 & $0.001 * *$ \\
\hline & 5 & 45.17 & 0.001 ** \\
\hline 4 & 5 & 8.36 & 0.11 \\
\hline \multirow[t]{4}{*}{ VARIA: 1} & 2 & -0.00 & 0.98 \\
\hline & 3 & -0.00 & 0.96 \\
\hline & 4 & -0.06 & 0.40 \\
\hline & 5 & -0.15 & $0.03 *$ \\
\hline \multirow[t]{3}{*}{2} & 3 & -0.00 & 0.98 \\
\hline & 4 & -0.06 & 0.42 \\
\hline & 5 & -0.15 & $0.03 *$ \\
\hline \multirow[t]{2}{*}{3} & 4 & -0.05 & 0.43 \\
\hline & 5 & -0.15 & $0.03^{*}$ \\
\hline 4 & 5 & -0.10 & 0.16 \\
\hline
\end{tabular}

SMEA: spinal muscle electrical activities; RMS: root mean square; VARIA: variability;

1 ; erect standing posture, $2 ; 30^{\circ}$ spinal flexion, $3 ; 45^{\circ}$ spinal flexion, $4 ; 90^{\circ}$ spinal flexion and $5 ; 30^{\circ}$ spinal extension, ${ }^{*}$ significant at 0.05 level, $* *$ significant at 0.001 leve 


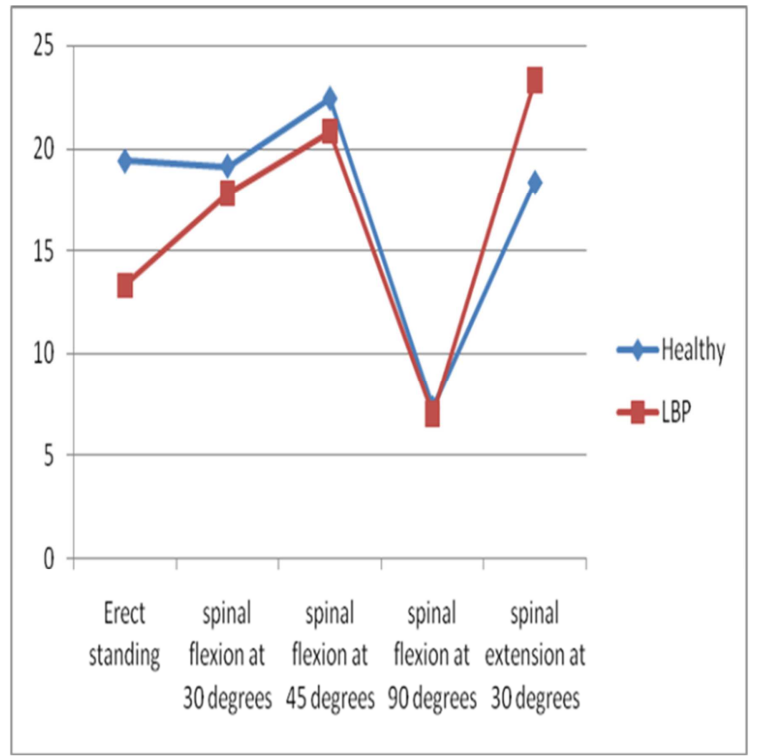

Figure 3. Graphic representation showing Electrical Activities in the Spinal Muscles at different Postures for the patients and apparently healthy control group.

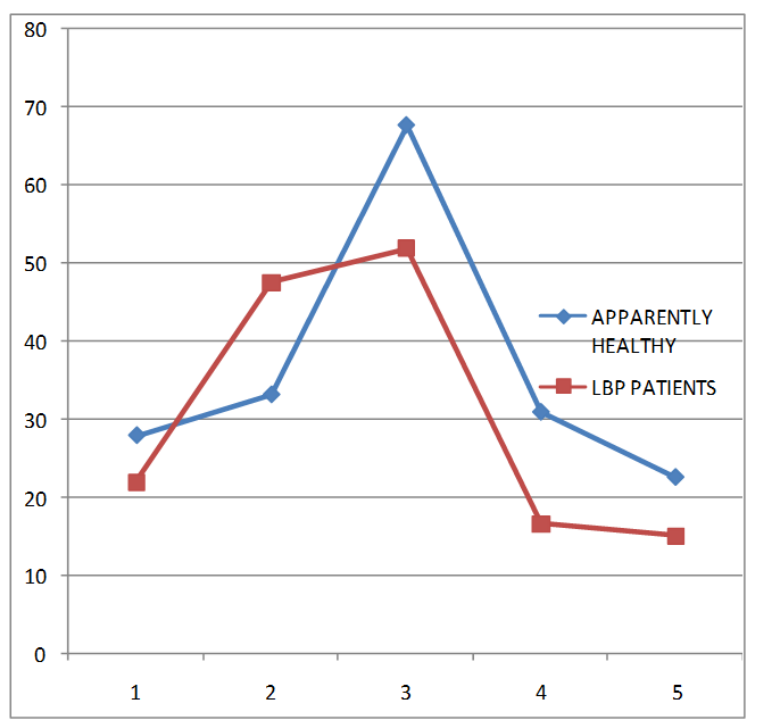

Figure 4. Graphic representation of Root Mean Square at different Postures for the patients with low back pain and apparently healthy control group.

1: erect standing posture, $2: 30^{\circ}$ spinal flexion, $3: 45^{\circ}$ spinal flexion, $4: 90^{\circ}$ spinal flexion and $5: 30^{\circ}$ spinal extension,

\subsection{Comparison of Spinal Muscle Electrical Activities (SMEA), Root Mean Square (RMS) and Variability Between Patients with LBP and Apparently Healthy Participants}

The result showed that at erect standing there were significant differences between the SMEA of the patient with LBP and that of the age matched apparently healthy participants $(t=2.04, p=0.05)$. Similar trend was observed for all other positions excluding comparison at $30^{\circ}$ spinal extension where there was no significant difference $(\mathrm{t}=$ $0.20 ; \mathrm{p}=0.84)$, (Table 8). Also, there were significant differences between the RMS of patients with LBP and the age matched apparently healthy participants at $30^{\circ}, 45^{\circ}$ and $90^{\circ}$ spinal flexion $(\mathrm{t}=2-79, \mathrm{p}=0.01 ; \mathrm{t}=2.61, \mathrm{p}=0.01 ; \mathrm{t}=$ $5.19 ; \mathrm{p}=0.001$ respectively). Typical graphs obtained for some participants are presented from figures 5 to 8 . However, the result of Variability showed that there were no significant differences between the variability of patients with LBP and the age matched apparently healthy participants (Table 8).

Table 8. Comparison of SMEA, RMS and Variability between Patients with LBP and Apparently healthy participants at different spinal Postures

\begin{tabular}{|c|c|c|c|c|}
\hline \multicolumn{5}{|c|}{ Patients with LBP Apparently Healthy } \\
\hline Postures & Mean SD & Mean SD & $\mathbf{T}$ & $\mathbf{P}$ \\
\hline SMEA: Erect & $18.78 \pm 13.30$ & $27.46 \pm 19.37$ & 2.04 & $0.05 *$ \\
\hline $30^{\circ} \mathrm{f}$ & $46.35 \pm 17.77$ & $62.54 \pm 19.12$ & 3.45 & $0.001 * *$ \\
\hline $45^{\circ} \mathrm{f}$ & $48.35 \pm 20.83$ & $60.70 \pm 22.40$ & 2.24 & $0.03 *$ \\
\hline $90^{\circ} \mathrm{f}$ & $10.74 \pm 6.99$ & $21.13 \pm 7.35$ & 5.70 & $0.001 * *$ \\
\hline $30^{\circ} \mathrm{ext}$ & $20.64 \pm 23.33$ & $19.59 \pm 18.32$ & -0.20 & 0.84 \\
\hline RMS:Erect & $22.01 \pm 14.93$ & $27.92 \pm 18.01$ & 1.40 & 0.17 \\
\hline $30^{\circ} \mathrm{f}$ & $47.60 \pm 17.75$ & $33.15 \pm 22.51$ & 2.79 & $0.01 *$ \\
\hline $45^{\circ} \mathrm{f}$ & $51.94 \pm 19.84$ & $67.72 \pm 27.02$ & 2.61 & $0.01^{*}$ \\
\hline $90^{\circ} \mathrm{f}$ & $16.70 \pm 6.62$ & $30.91 \pm 13.55$ & 5.19 & $0.001 * *$ \\
\hline $30^{\circ} \mathrm{ext}$ & $15.14 \pm 13.45$ & $22.55 \pm 21.38$ & 1.62 & 0.11 \\
\hline VARIA: Erect & $0.20 \pm 0.13$ & $0.15 \pm 0.13$ & -1.42 & 0.16 \\
\hline $30^{\circ} \mathrm{f}$ & $0.16 \pm 0.10$ & $0.15 \pm 0.12$ & -0.38 & 0.71 \\
\hline $45^{\circ} \mathrm{f}$ & $0.17 \pm 0.09$ & $0.15 \pm 0.05$ & -1.10 & 0.28 \\
\hline $90^{\circ} \mathrm{f}$ & $0.31 \pm 0.45$ & $0.21 \pm 0.29$ & -1.10 & 0.28 \\
\hline $30^{\circ} \mathrm{ext}$ & $0.40 \pm 0.35$ & $0.30 \pm 0.49$ & -0.88 & 0.38 \\
\hline
\end{tabular}

f: flexion; ext: extension; ${ }^{*}$ significant at 0.05 level, ${ }^{* *}$ significant at 0.001 level.

\section{Discussion}

Electromyography describes muscle function through analysis of the electrical signals emanating during activation of muscular contractions [28]. Myoelectric signals are formed by physiological variations in the state of muscle fiber membranes [29]. The result of this study showed that there were no significant differences in the anthropometric parameters of the low back pain patients and the apparently healthy control. There was a gradual increase in mean pain intensity from erect standing to forward flexion, reaching the peak at $90^{\circ}$ spinal flexion for theLBP patients.

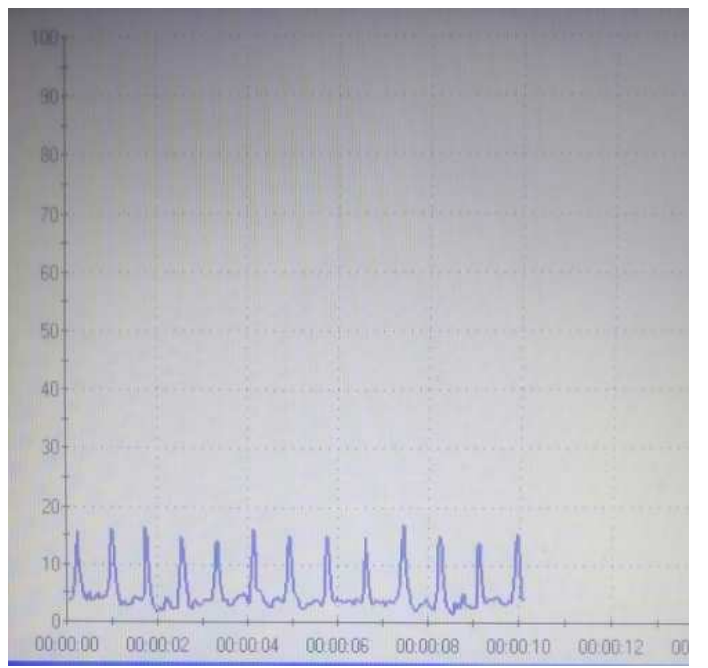

Figure 5. RMS graph of a patient with low back pain at erect standing. 


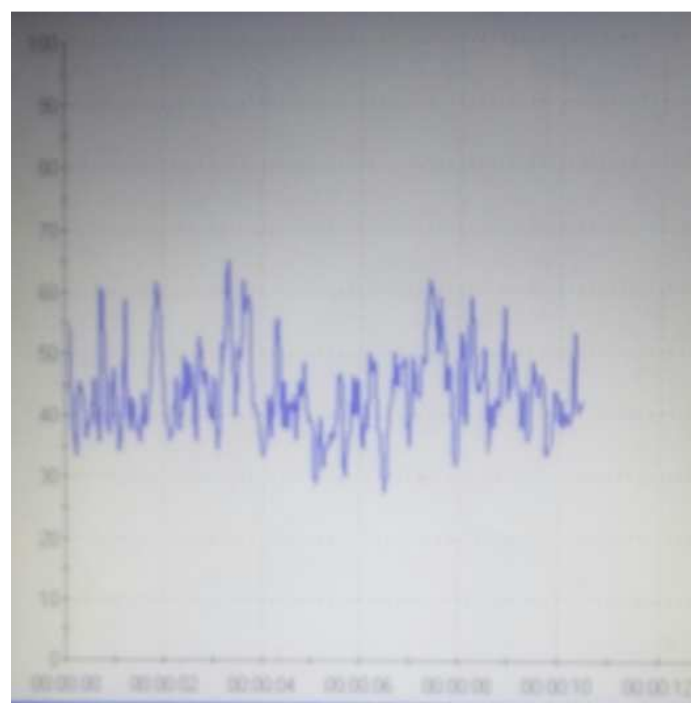

Figure 6. RMS graph of a patient with low back pain at $90^{\circ}$ spinal flexion posture.

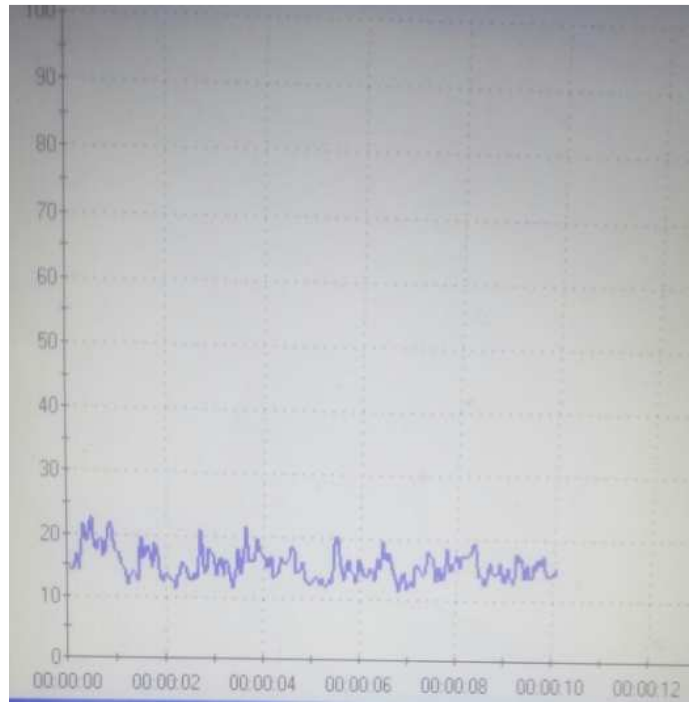

Figure 7. RMS graph of an apparently healthy participant at erect standing.

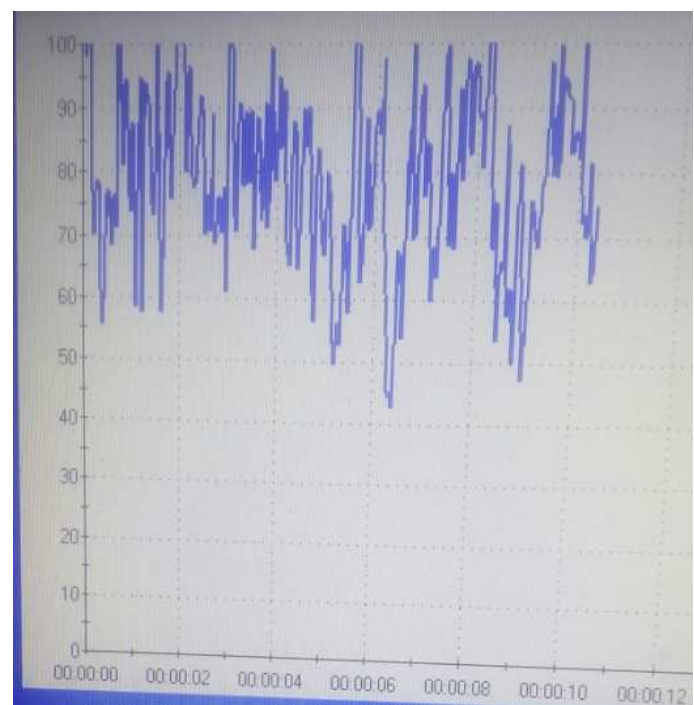

Figure 8. RMS graph of an apparently healthy participant at $90^{\circ}$ spinal flexion posture.
The pain intensities were significantly higher at $90^{\circ}$ spinal flexion and $30^{\circ}$ extension compared to other spinal postures for patients with LBP. It has been documented by May and Loma [23] that postures aggravate or relieve low back pain because it affects anatomy and physiology of the spine. The above authors also reviewed the reports of Adams et al. [11] and Bridger [10] where they observed that with flexion of the lumbar spine the intervertebral disc is compressed anteriorly, causing a posterior displacement of the nucleus pulposus and an increase in intra-discal pressure thereby aggravating pain. Also, the spinal and vertebral canals are widened while the spinal cord is tensioned, thus, aggravating pain intensity when the spinal posture approached $90^{\circ}$ Spinal flexion. The most consistent findings amongst previous reportswere that positions of flexion were largely identified as aggravating factors. Positionsof flexion, such as sitting or bending were extremely rarely reported to relieve symptoms, whereas positions of extension or lying down does [23].

The Spinal Muscle Electrical Activities (SMEA) of patients with LBP were significantly lower at all postures compared to that of healthy participants. This implied that there were lower neuromuscular efficiencies or performances in the para-vertebral muscles of patients compared to that of healthy control participants. Furthermore, the SMEA increased gradually to reach the peak at $45^{\circ}$ spinal flexion; declined at $90^{\circ}$ spinal flexion after which there was a sharp rise at $30^{\circ}$ extension in both groups. It was also found that SMEA were significantly higher at $30^{\circ}$ and $45^{\circ}$ spinalflexion than erect standing. This could be attributed to increase in muscle activities to protect the spine and counter-balance the effect of gravity as forward flexion increases. Different postures alter muscle activity; during standing, back muscles show slight, intermittent or no activity, with activity influenced by the position of the spine in reference to the line of gravity [23], [30]. The degree of shift of centre of gravity determines to what extent the more contra-lateral muscle groups will need to work to maintain control. During sitting muscle activity is minimal so loads tend to be transferred to local soft tissues [31]. During forward flexion, the posterior muscles are activated and offer resistance in order to prevent the head and torso mass, when subjected to gravity, from collapsing forward uncontrolled. Simultaneously, the viscoelastic tissues stretched and gradually develop increasing passive forces [32].

However, this study found that SMEA at $90^{\circ}$ spinal flexion and $30^{\circ}$ spinal extension were not significantly different from that of erect standing. This lent credence to the old report of Dolan and Mannion [32]. The authors explained that as the passive forces exceed the magnitude of the muscle forces are no longer required and become silent and that further flexion is accomplished by contraction of abdominal muscles. Spinal EMG activity increases as the lumbar paraspinal muscles support the trunk at a greater angle to gravity and at near full flexion, ligaments take over the burden of supporting the trunk, and lumbar paraspinal SEMG activity drops, often to a level less than the activity recorded upright standing. This paraspinal relaxation on terminal flexion was first reported in 
the late 1940s by Allen [33].

The RMS of patients with LBP was significantly lower at erect standing, 45, 90degrees spinal flexion and 30 degrees extension. We deduced that physiological activities and power of signals in the motor units during contractions of the para-spinal muscles were lower for the patients at these postures. An old dated study by Allen [33] reported that Spinal EMG signals from the lumbar para-spinal muscles are generally low in quiet standing. The high physiological activities observed at 30 degrees spinal flexion only might be attributed to increase in muscular contraction and higher potential energy required to move the spine from the erect neutral standing (a point of higher centre of gravity) to stooping position. Other factors can influence the capture of the EMG signal and these includes physiological type of muscle fiber, nerve fiber conduction, body temperature; anatomical (as a diameter of the muscle fiber), position (depth) of the muscle in relation to the electrode and thickness of the skin; and technical, related to instrumentation during EMG analysis, involving aspects related to the capture and processing of data [34-35]. There was no difference in the variability of the 2 groups but there are variations in the variability within the groups especially between erect standing $30^{\circ}$; and $45^{\circ}$ spinal flexion compared to $30^{\circ}$ spinal extension. German [20] reported that there are different levels of variation for different muscles and that these could be related to different functions or different tasks of the muscles. This study has some potential limitation findings because SMEA recorded were not specific for individual group of muscles because surface electrodes were utilized.

\section{Conclusion}

It was concluded that patients with low back pain have lower neuromuscular efficiencies and muscle performances than the apparently healthy participants. Also, the Spinal Muscle Electrical Activities and Root Mean Square of patients with low back pain differed at different postures. We recommend that electromyographic activities should be taken as part of routine assessment, and special attention should be focused on spinal postures that will improve physiological properties of para-vertebral muscles especially in exercise prescription for the management of patients with low back pain.

\section{References}

[1] Bernard BP. Musculoskeletal disorders and workplace factors: A critical review of epidemiologic evidence for work-related musculoskeletal disorders of the neck, upper extremity, and low back Cincinnati, OH: National Institute for Occupational Safety, U. S. Department of Health and Human Services; 1997.

[2] Winkel J, Westgaard RH. Ergonomic intervention research for musculoskeletal health-some future trends. In 33rd Nordic Ergonomics Society Conference, University of Tampere;
2001; Tampere. p. 28-32.

[3] Mitchell TOPB, Burnett AF, Straker L, Smith A. Regional differences in lumbar spinal posture and the influence of low back pain. BMC Musculoskeletal Disorders. 2008 November 18; 9 (1): p. 1.

[4] Tüzün C, Yorulmaz I, Cindaş A, Vatan S. Low back pain and posture. Clinical rheumatology. 1999 June 1; 18(4): p. 308312 .

[5] Widhe T. Spine: posture, mobility and pain. A longitudinal study from childhood to adolescence. European Spine Journal. 2001 April; 10 (2): p. 118-123.

[6] McKenzie R, May S. The lumbar spine: mechanical diagnosis and therapy. Orthopedic Physical Therapy. 2003 June 1; 1.

[7] O'Sullivan PB, Mitchell T, Bulich P, Waller R, Holte J. The relationship beween posture and back muscle endurance in industrial workers with flexion-related low back pain. Manual therapy. 2006 November 30;: p. 264-271.

[8] Dankaerts W, O'Sullivan P, Burnett A, Straker L. Differences in sitting postures are associated with nonspecific chronic low back pain disorders when patients are subclassified. Spine. 2006 March 15; 31 (6): p. 698-704.

[9] Dankaerts W, O'Sullivan P, Burnett A, Straker L, Davey P, Gupta R. Discriminating healthy controls and two clinical subgroups of nonspecific chronic low back pain patients using trunk muscle activation and lumbosacral kinematics of postures and movements: a statistical classification model. Spine. 2009 July 1; 34 (15): p. 1610-1618.

[10] Bridger RS. Introduction to ergonomics London: Taylor \& Fancis; 2003.

[11] Adams M, Bogduk N, Burton K, Dolan P. The Biomechanics of Back Pain. 2nd ed. Edinburgh: Churchill Livingstone; 2006.

[12] Onigbinde AT, Fasuba. Effects of straight leg raising and lumbar rotation techniques in patients with lumbar radiculopathy. Rehab Acta. 2015; 1 (1): p. 17-21.

[13] Pheasant S. Bodyspace anthropometry, ergonomics, and the design of work. 2nd ed. London: Taylor \& Francis Ltd; 1998.

[14] Corlett NE. Static muscle loading and the evaluation of posture. In Wilson JR, Corlett EN. Evaluation of Human Work. London: Taylor \& Francis; 2005. p. 453-496.

[15] Biedermann HJ, Shanks GL, Inglis J. Median frequency estimates of paraspinal muscles: reliability analysis. Electromyography and clinical neurophysiology. 1989 December; 30 (2): p. 83-88.

[16] Biedermann HJ, Shanks GL, Forrest WJ, Inglis J. Power Spectrum Analyses of Electromyographic Activity: Discriminators in the Differential Assessment of Patients with Chronic Low-Back Pain. Spine. 1991 October 1; 16 (10): p. 1179-1184.

[17] Garcia MC, Vieira TM. Surface electromyography: Why, when and how to use it. 17-28. Revista andaluza de medicina del deporte. 2011; (1): p. 17-28.

[18] Werner C, Ullrich P, Geravand M, Peer A, Hauer K. Evaluation Studies of Robotic Rollators by the User Perspective: A Systematic Review. Gerontology. 2016 March; 24. 
[19] Alkan A, Günay M. Identification of EMG signals using discriminant analysis and SVM classifier. Expert Systems with Applications. 2012 January 31; 39 (1): p. 44-47.

[20] German RZ, Crompton AW, Thexton AJ. Variation in EMG activity: a hierarchical approach. Integrative and comparative biology. 2008 August; 48 (2): p. 283-293.

[21] Fukuda TY, Alvarez AS, Nassri LF, Godoy CM. Quantitative electromyographic assessment of facial muscles in cross-bite female children. Rev. bras. eng. biomed. 2008 August; 24(2): p. 121-129.

[22] Daintith J. A dictionary of physics: Oxford reference online. 6th ed. Oxford: Oxford University Press; 2009.

[23] May S, Lomas D. Posture the Lumbar Spine and Back Pain. International Encyclopedia of Rehabilitation. 2010.

[24] Clapis P, Davis SM, Davis RO. Reliability of inclinometer and goniometric measurements of hip extension flexibility using the modified Thomas test. Physiotherapy theory and practice. 2008 January 1; 24 (2): p. 135-141.

[25] Kolber MJ, Hanney WJ. The reliability and concurrent validity of shoulder mobility measurements using a digital inclinometer and goniometer: a technical report. International journal of sports physical therapy. 2012 June; 7 (3): p. 306.

[26] Cram JR, Kasman GS, Holtz J. Introduction to Surface Electromyography Gaithersburg, Maryland: Aspen Publishers Inc; 1998.

[27] Finneran MT. Physiological imaging of the low back: normative values for large array surface electromyography. J Disability. 2001 August;: p. 15-21.
[28] Kamen G. Electromyographic kinesiology. In Gordon D, Robertson E, Caldwell GE, Hamill J, Kamen G, Whittlesey SN. Research Methods in Biomechanics. Champaign, IL: Human Kinetics Publ; 2004.

[29] Merletti R, De Luca CJ. New techniques in surface electromyography. Computer aided electromyography and expert systems. 1989; 2: p. 115-124.

[30] Bogduk N. Clinical anatomy of the lumbar spine and sacrum. 4th ed. Edinburgh: Elsevier Health Sciences; 2005.

[31] McKenzie R, May S. The lumbar spine: mechanical diagnosis and therapy. Orthopedic Physical Therapy. 2003 June 1; 1.

[32] Dolan P, Mannion AF, Adams MA. Fatigue of the Erector Spinae Muscles: A Quantitative Assessment Using" Frequency Banding" of the Surface Electromyography Signal. Spine. 1995 January 15; 20 (2): p. 149-59.

[33] Allen CEL. Muscle action potentials used in the study of dynamic anatomy. British Journal of Physical Medicine. 1948; 11: p. 66-73.

[34] Fridlund AJ, Cacioppo JJ. Guidelines for human EMG research. Psychophysiology. 1986 September 1; 23 (5): p. 1496-500.

[35] Ervilha UF, Duarte M, Amadio A. Estudosobreprocedimentos de normalização do sinaleletromiográficodurante o movimentohumano. RevistaBrasileira de Fisioterapia. 1998; 3 (1): p. 15-20. 